\title{
Structure of cognitive disorders in patients with primary episode of bipolar affective disorder
}

\author{
Yuriy Mysula, Olena Venger \\ Department of Psychiatry, Narcology and Medical Psychology, "Ivan Horbachevsky" \\ National Medical University, Ternopil, Ukraine
}

\begin{abstract}
Bipolar affective disorder (BAD) is one of the most pressing problems of modern psychiatry; cognitive impairment has one of the leading places in the structure of symptoms of bipolar disorder.

The aim of the study was to compare the structure of cognitive disorders in patients with a primary episode (PE) of BAD, based on sex and clinical version of the disease debut.

Results and discussion. Based on clinical examination of 65 men and 88 women with PE of BAD was revealed that the basis of cognitive manifestations of depressive type of disorder constitute of slowing of cognition, attention deficit and executive functions: slow thinking, impaired attention concentration, difficulties in planning and decision making, rigidity of thinking. Cognitive symptoms of manic type of PE of $B A D$ were based on disorders of thinking: accelerated thinking, increased self-esteem, exaggeration of own possibilities, disturbance of concentration of attention, difficulties in planning and decision making. The mixed version of $P E$ of $B A D$ was characterized by a complex combination of cognitive symptoms, the spectrum of which included both manifestations of thinking disorders and difficulty of attention concentrating.

Conclusions. In the PE of BAD, the spectrum of cognitive symptomatology is determined by the clinical variant: in depressive the phenomena of cognitive slowing, attention deficit and performance functions are dominated, in the manic - the disorder of thinking, and in the mixed variant, all the spectrum of disorders are present; gender influence has no significant effect on the structure of cognitive symptomatology.
\end{abstract}

Keywords: bipolar affective disorder, primary episode, cognitive disorders

\section{INTRODUCTION}

Bipolar affective disorder (BAD) is one of the most pressing problems in modern psychiatry. The disease of BAD is characterized by a high prevalence, high level of comorbidity, dependence form psychoactive substances, decreased quality of life and social functioning of patients, high suicidal risk and the need for long-term treatment [1-4]. At the same time, the diagnosis of BAD at the initial stage is insufficient, as this disease is characterized by a significant polymorphism of symptoms, and modern methods of early diagnosis of it are imperfect [5-7].

In recent years, particular attention has been paid to the study of the features of cognitive disorders in BAD. Today, disorders of cognitive functions are considered as an important component of the clinical picture of BAD, while cognitive disorders are manifested in both the manic and depressive phase and in the period of intermission [8-10]. However, studies of the features of cognitive disorders in the PE of BAD have not yet been conducted, which made impossible to understand 
the pathodynamics of cognitive disorders since the first manifestations of the disease. Looking on the importance of the study of cognitive dysfunction in PE of BAD, we have implemented a comprehensive study of the state of cognitive sphere of patients with PE of BAD.

\section{AIM}

The aim of the study was to compare the structure of cognitive disorders in patients with a PE of $B A D$, based on sex and clinical type of the disease debut.

\section{MATERIALS AND METHODS}

Adhering to the principles of biomedical ethics based on our informed consent, were clinically examined 153 patients (65 men and 88 women) with PE of BAD who were treated in the Ternopil Regional Psychoneurological hospital during 20112016 years. The mean age of the examined patients at the time of symptomatic onset was 21.3 \pm 6.5 years (median 19.0 years, interquartile range $17.0-22.0$ years), men $20.5 \pm 5.8$ years ( 18.0 years, 17.0-21.0 years), women $21.9 \pm 6,9$ years $(19,0$ years, $18.5-22.5$ years), age at the time of seeking medical help and examination - accordingly $21.4 \pm$ 6.4 years (19.0 years, $18.0-22.0$ years), $20.7 \pm 5.7$ years (18.0 years, $17.0-21.0$ years) and $22.0 \pm 6.9$ years (19.0 years, $18.5-22.5$ years).

The examined men and women were divided into three groups, depending on the clinical type of the course of PE of BAD: with the prevalence of depressive symptoms (depressive type), the number of 119 patients (44 men and 75 women); with predominance of manic or hypomanic symptoms (manic type), number of 23 persons ( 15 men and 8 women), and with simultaneous presence of depressive and manic symptoms, or with rapid phase change (mixed type), number of 11 persons (6 men and 5 women).

Statistical analysis of differences was performed using Fisher's exact test. The level of statistical significance of differences over $95.0 \%$ $(p<0.05)$ was considered acceptable.

\section{RESULTS}

PE of BAD is accompanied by pronounced manifestations of cognitive dysfunction, the spectrum of which differs significantly depending on the clinical type of the disease debut (Table 1).

TABLE 1. The structure of cognitive impairment symptomatology in the examined patients with regard to sex and clinical type of PE of $B A D$

\begin{tabular}{|c|c|c|c|c|c|c|c|}
\hline \multirow{2}{*}{ Symptom } & \multicolumn{2}{|c|}{ Together } & \multicolumn{2}{|c|}{ Men } & \multicolumn{2}{|c|}{ Women } & \multirow{2}{*}{ years } \\
\hline & abs. & $\%$ & abs. & $\%$ & abs. & $\%$ & \\
\hline \multicolumn{8}{|c|}{ Depressive type of PE of BAD } \\
\hline Slow thinking & 108 & 90.8 & 39 & 88.6 & 69 & 92.0 & $>0.05$ \\
\hline Rigid thinking & 59 & 49.6 & 31 & 70.5 & 28 & 37.3 & $<0.01$ \\
\hline Accelerated thinking & 0 & 0.0 & 0 & 0.0 & 0 & 0.0 & $>0.05$ \\
\hline Increased self-esteem & 0 & 0.0 & 0 & 0.0 & 0 & 0.0 & $>0.05$ \\
\hline Exaggeration of own capabilities & 0 & 0.0 & 0 & 0.0 & 0 & 0.0 & $>0.05$ \\
\hline Disorders of attention & 112 & 94.1 & 40 & 90.9 & 72 & 96.0 & $>0.05$ \\
\hline Difficulty planning and decision making & 111 & 93.3 & 39 & 88.6 & 72 & 96.0 & $>0.05$ \\
\hline \multicolumn{8}{|c|}{ Manic type of PE of BAD } \\
\hline Slow thinking & 0 & 0.0 & 0 & 0.0 & 0 & 0.0 & $>0.05$ \\
\hline Rigid thinking & 0 & 0.0 & 0 & 0.0 & 0 & 0.0 & $>0.05$ \\
\hline Accelerated thinking & 20 & 87.0 & 14 & 93.3 & 6 & 75.0 & $>0.05$ \\
\hline Increased self-esteem & 14 & 60.9 & 11 & 73.3 & 3 & 37.5 & $>0.05$ \\
\hline Exaggeration of own capabilities & 16 & 69.6 & 12 & 80.0 & 4 & 50.0 & $>0.05$ \\
\hline Disorders of attention & 15 & 65.2 & 10 & 66.7 & 5 & 62.5 & $>0.05$ \\
\hline Difficulty planning and decision making & 2 & 8.7 & 1 & 6.7 & 1 & 12.5 & $>0.05$ \\
\hline \multicolumn{8}{|c|}{ A mixed type of PE of BAD } \\
\hline Slow thinking & 5 & 45.5 & 2 & 33.3 & 3 & 60.0 & $>0.05$ \\
\hline Rigid thinking & 2 & 18.2 & 1 & 16.7 & 1 & 20.0 & $>0.05$ \\
\hline Accelerated thinking & 3 & 27.3 & 2 & 33.3 & 1 & 20.0 & $>0.05$ \\
\hline Increased self-esteem & 4 & 36.4 & 3 & 50.0 & 1 & 20.0 & $>0.05$ \\
\hline Exaggeration of own capabilities & 6 & 54.5 & 4 & 66.7 & 2 & 40.0 & $>0.05$ \\
\hline
\end{tabular}




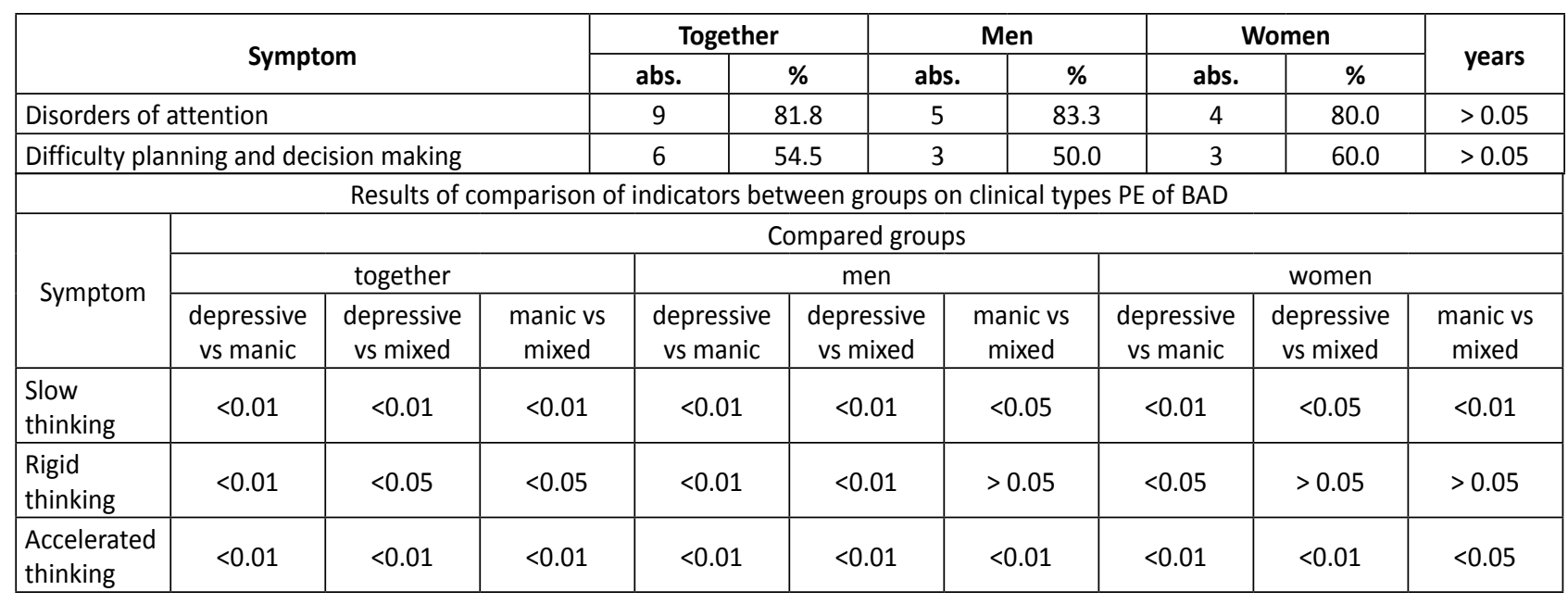

In the depressive type of PE of BAD, the basis of cognitive impairment is manifestations of cognitive slowing, attention deficit and performance functions (Fig. 1). Thus, the most widespread manifestations of cognitive dysfunction in patients with PE of BAD were the phenomena of delayed thinking, which were found in $90.8 \%$ of patients (in women slightly more often than in men-92.0\% versus $88.6 \%, p>0.05$ ), impaired concentration, which were found in $94.1 \%$ of patients (insignificant more often in women than men: $96.0 \%$ versus $90.9 \%, p>0.05$ ), and difficulties in planning and decision-making, found in $93.3 \%$ (slightly more frequent in women than in men: $96.0 \%$ versus $88.6 \%, p>0.05)$. Less spread was the rigidity of thinking that was found in $49.6 \%$ of patients (in men more often than women $-70.5 \%$ versus $37.3 \%, p<0.01)$.

In contrast to the depressive, in the manic type of PE of BAD core cognitive symptomatology was found in disorders of thinking (Fig. 2). Common symptoms were accelerated thinking in $87.0 \%$ of patients (more often in men than in women: $93.3 \%$ versus $75.0 \%(p>0.05)$, increased self-esteem - in $60.9 \%$ of patients (in men more often than women: $73.3 \%$ versus $37.5 \%, p>0.05$ ), and an increase in own opportunities $-69.6 \%$ (men more often than women: $80.0 \%$ versus $50.0 \%, p>$ $0.05)$. Concentration disorders were also observed in this group, but their prevalence was lower than in the depressed type $-65.2 \%$ of patients (slightly more frequent in men than in women: $66.7 \%$ against $62.5 \%, p>0.05$ ) It should also be noted that the concentration difficulties in patients with a manic type of PE of BAD were different from those that were typical for patients with a depressive type. Depressive type was associated with the difficulties of attention concentration and the inability of patients to focus on individual objects, as well as the rapid change of focus of attention due to the acceleration of mental activity. Patients with a manic type of PE of BAD did not experience

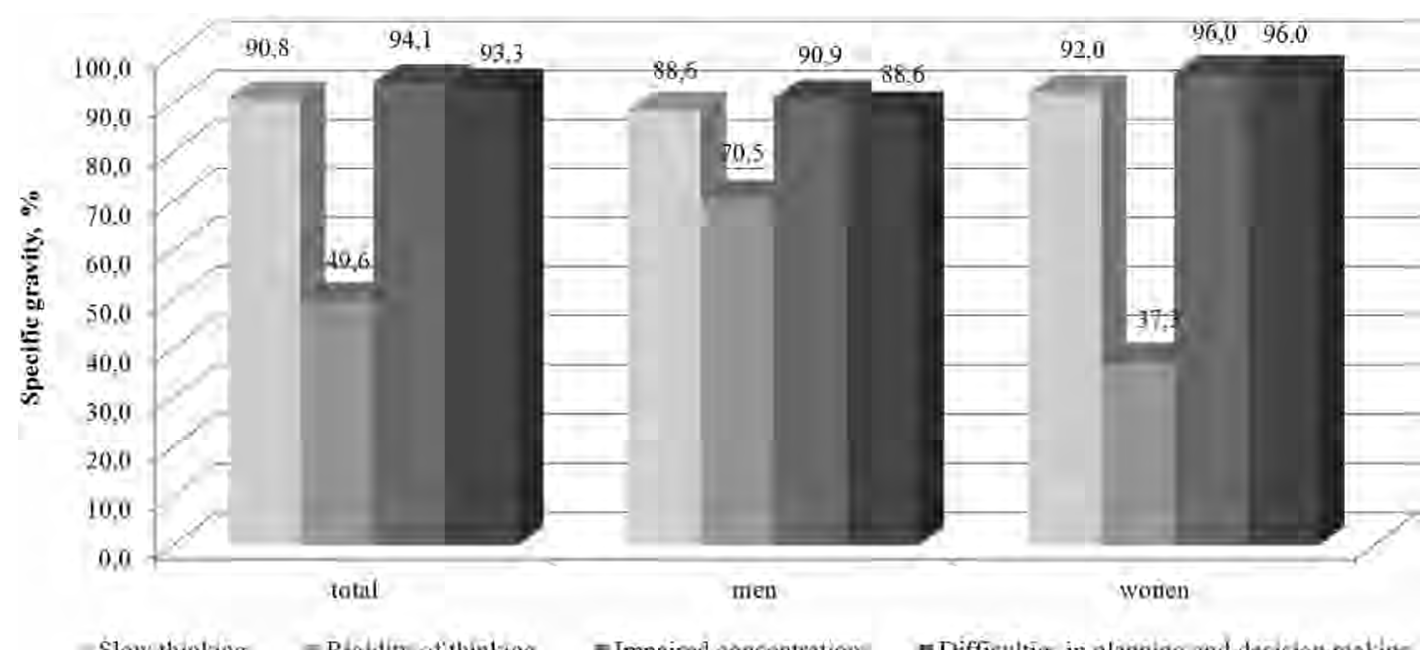

FIGURE 1. The structure of the symptomatology of cognitive disorders in patients with depressed PE of BAD 


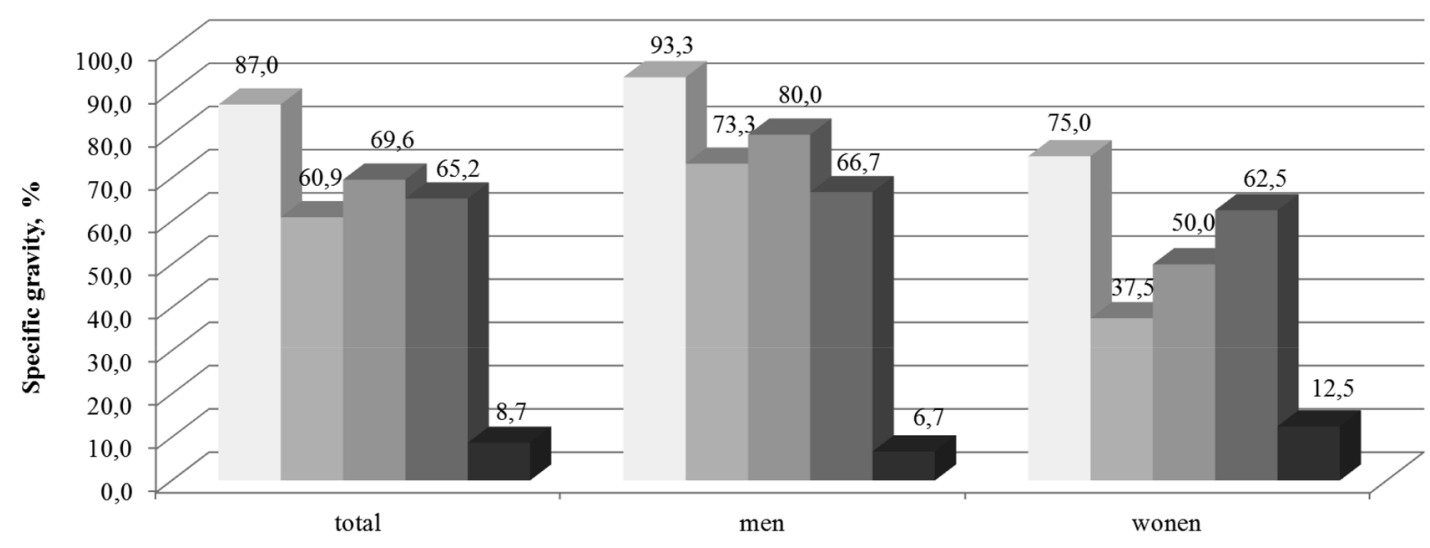

Accelerated thinking $\square$ Heightened self-esteem $\square$ Exagerration $\square$ Impaired concentration $\square$ Difficulties in planning and decision making

FIGURE 2. The structure of the symptomatology of cognitive disorders in patients with manic type of PE of BAD

difficulties in planning and decision-making; they were detected only in isolated cases - in $8.7 \%$ of patients, in women slightly more often than in men: $12.5 \%$ versus $6.7 \%, p>0.05$ ).

The mixed type of PE of BAD was characterized by a complex combination of cognitive symptoms, the spectrum of which included both manifestations of thinking disorders and difficulty concentrating attention, which may be explained by the polymorphism and instability of clinical manifestations in this group (Fig. 3). Thus, the most common were attention disorders $-81.8 \%$ of patients (almost equally common in men and women: $83.3 \%$ and $80.0 \%$, accordingly, $p>0.05$ ), as well as impaired performance in the difficulty of planning and decision-making: $54.5 \%$ (more often in women than in men: $60.0 \%$ versus $50.0 \%, p>0.05$ ) and exaggeration of their own capabilities in $54.5 \%$ of patients (men more often than women: $66.7 \%$ vs.
$40.0 \%, p>0.05)$. Slightly less frequent manifestations of slow thinking were present in $45.5 \%$ of all patients (more often in women than in men: $33.3 \%$ versus $60.0, p>0.05$ ), increased self-esteem - in $36.4 \%$ patients (more often in men than in women: $50.0 \%$ versus $20.0 \%, p>0.05$ ), and accelerated thinking - in $27.3 \%$ of all patients (in men more often than in women: $33.3 \%$ versus $20.0 \%, p$ $>0.05$ ), and the most rare symptom was rigid thinking, which was found in $18.2 \%$ of all patients (slightly more common in men than in women: $20.0 \%$ versus $16.7 \%, p>0.05$ ).

\section{DISCUSSION}

The data received by us regarding the presence of cognitive disorders in patients with PE of BAD supplement the current scientific data on cognitive dysfunction in bipolar disorder. In particular, it

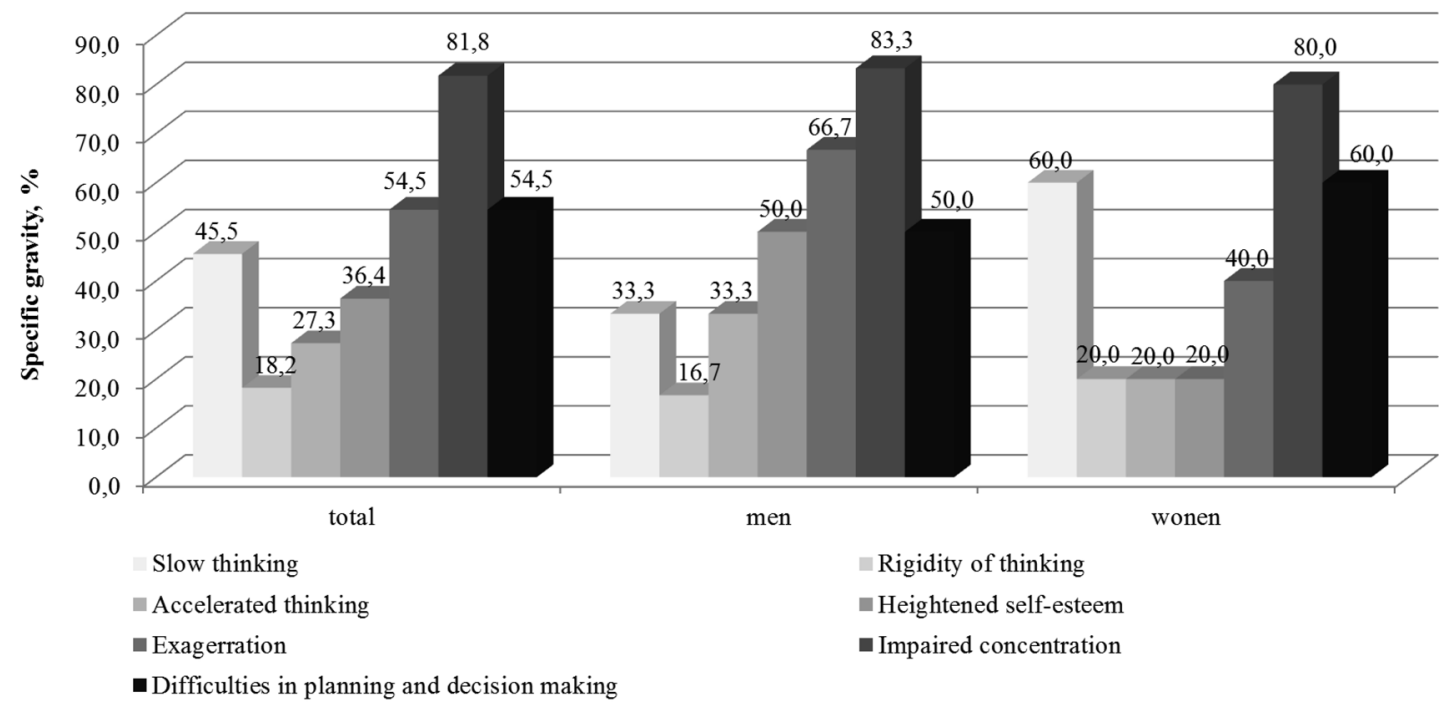

FIGURE 3. The structure of the symptomatology of cognitive disorders in patients with mixed PE of BAD 
is consistent with the findings of S.Q. Borges et al. (2019) [11], C. del Mar Bonnín at al. (2019) [12], Y. Zhu et al. (2019) [13], which highlighted the pronounced cognitive impairment in patients with $B A D$, in particular, deficits in executive function, attention, and memory. The results obtained are consistent with the context of current understanding of cognitive impairment as one of the earliest manifestations of BAD, not only in nosological (Lima IM, Peckham AD et Johnson SL (2018) [14], N. Xu, B. Huggon, KEA Saunders (2019) [15]), but also at the pre-nosological stages (A. Ratheesh et al. (2013) [16]). At the same time, it should be noted that the features of cognitive functioning in the primary episode of BAD have so far remained unexplored; looking on the above, our data represent an important complement to existing studies that have identified cognitive impairment in the early stages of the disease. Thus, S. Lera-Miguel et al. (2015) provide data on the presence of the same cognitive disorders in children with BAD as adults [17], and R.G. Nieto and F.X. Castellanos (2011) reported the presence of signs disorders of verbal learning, memory, speed of information processing, working memory, executive function, and attention in children with BAD [18]. Y. Mysula and $O$. Venger (2020) found high prevalence of asthenic, somatovegetative, and obsessive symptoms that influences the cognition of this patients [19]. Also important is the validation of a number

of studies (A.T. Peters et al., 2014 [20], S. Bourne, 2013 [21] ) regarding the association of depressive and manic symptoms with impaired cognitive functioning; The peculiarity of our study is the selection of patients with different clinical variants of PE of BAD into separate groups, which allowed us to show the qualitative difference in the structure of cognitive disorders in depressive, manic and mixed variants.

\section{CONCLUSIONS}

The PE of BAD is accompanied by a wide range of disorders of cognitive function that are associated with disorders of thinking as well as disordered attention and memory. The determining factor for the spectrum of cognitive disorders is the clinical type of the PE. In this case, the depressive type is associated with manifestations of cognitive slowing, attention deficit and performance functions, in the manic type main cognitive symptomatology is based on disorders of thinking, and in the mixed type there are the whole spectrum of cognitive disorders. There are no gender differences in the structure of cognitive disorders in the PE of BAD. The identified patterns can be used for early detection and prediction of BAD, as well as for the development of treatment and rehabilitation and preventive measures in this pathology.

Conflict of interest: none declared Financial support: none declared

\section{REFERENCES}

1. Hayes JF, Miles J, Walters K, King M, Osborn DPJ. A systematic review and meta-analysis of premature mortality in bipolar affective disorder. Acta Psychiatrica Scandinavica. 2015 Jun;131(6):417-25.

2. Marwaha S, Durrani A, Singh S. Employment outcomes in people with bipolar disorder: A systematic review. Acta Psychiatrica Scandinavica. 2013 Sep; 128(3):179-93.

3. Crump C, Sundquist K, Winkleby MA, Sundquist J. Comorbidities and mortality in bipolar disorder: A Swedish national cohort study. JAMA Psychiatry. 2013 Sep; 70(9):931-939.

4. Patel R, Shetty $H$, Jackson R, Broadbent M, Stewart R, Boydell J, McGuire P, Taylor $M$. Delays before diagnosis and initiation of treatment in patients presenting to mental health services with bipolar disorder. PLOS One. 2015 May;10:126-129.

5. Forty $L$, Ulanova $A$, Jones $L$, Jones $I$, Gordon-Smith K, Fraser C, Farmer A, McGuffin P, Lewis CM, Hosang GM, Rivera $M$, Craddock N. Comorbid medical illness in bipolar disorder. Br J Psychiatry. 2014 Dec; 205(6):465-72.
6. Tseng PT, Zeng BS, Chen YW, Wu MK, Wu CK, Lin PY. A meta-analysis and systematic review of the comorbidity between irritable bowel syndrome and bipolar disorder. Medicine (Baltimore). 2016 Aug; 95(33):e4617.

7. Faedda GL, Serra G, Marangoni C, Salvatore P, Sani G, Vázquez GH, Tondo L, Girardi P, Baldessarini RJ, Koukopoulos A. Clinical risk factors for bipolar disorders: A systematic review of prospective studies. J Affect Disord. 2014 Oct;168:314-21.

8. Solé $B$, Jiménez $E$, Torrent $C$, Reinares $M$, del Mar Bonnin C, Torres I, Varo C, Grande I, Valls E, Salagre E, Sanchez-Moreno J, Martinez-Aran A, Carvalho AF, Vieta E. Cognitive Impairment in Bipolar Disorder: Treatment and Prevention Strategies. Int J Neuropsychopharmacol. 2017 Aug 1; 20(8):670-680.

9. Sanches M, Bauer IE, Galvez JF, Zunta-Soares GB, Soares JS. The Management of Cognitive Impairment in Bipolar Disorder: Current Status and Perspectives. Am J Ther. 2015 Nov-Dec; 22(6):477-86.

10. Murri BM, Respino M, Proietti L, Bugliani M, Pereira B, D’Amico E, Sangregorio F, Villaa
V, Trinchero V, Brugnolo A, Girtler N, Nobili $\mathrm{F}$, Amore M. Cognitive impairment in late life bipolar disorder: Risk factors and clinical outcomes. Journal of Affective Disorders. 2019 Jul; 257:166-72.

11. Borges SQ, Corrêa TX, Trindade IO, Amorim RF, de Vilhena Toledo MA Cognitive impairment in bipolar disorder Neuroprogression or behavioral variant frontotemporal dementia? Dementia \& Neuropsychologia. 2019 Oct./Dec.; 13(4):475-80.

12. del Mar Bonnín C., Reinares M., MartínezArán A., Jiménez E., Sánchez-Moreno J., Solé B., Montejo L., Vieta E. Improving Functioning, Quality of Life, and Well-being in Patients With Bipolar Disorder. International Journal of Neuropsychopharmacology. 2019; 22(8):467-477.

13. Zhu Y, Womer FY, Leng $H$, Chang M, Yin Z, Wei Y, Zhou Q, Fu S, Deng X, Lv J, Song Y, Ma Y, Sun X, Bao J, Wei S, Jiang X, Tan S, Tang Y, Wang F. The Relationship Between Cognitive Dysfunction and Symptom Dimensions Across Schizophrenia, Bipolar 
Disorder, and Major Depressive Disorder. Front Psychiatry. 2019 Apr;10:253.

14. Lima IMM, Peckham AD, Johnson SL. Cognitive deficits in bipolar disorders: Implications for emotion. Clin Psychol Rev. 2015 Feb;59:126-136.

15. Xu N, Huggon B, Saunders KEA. Cognitive Impairment in Patients with Bipolar Disorder: Impact of Pharmacological Treatment. CNS Drugs. 2020 Jan;34(1):29-46.

16. Ratheesh A, Lin A, Nelson B, Wood SJ, Brewer W, Betts J, Bechdolf A.

Neurocognitive functioning in the prodrome of mania - an exploratory study. Journal of Affective Disorders. 2013;147(1-3): 441-445.
17. Lera-Miguel S, Andres-Perpina S, Fatjo-Vilas M, Fananas L, Lazaro L. Two-year follow-up of treated adolescents with early-onset bipolar disorder: Changes in neurocognition. Journal of Affective Disorders. 2015;172:48-54.

18. Nieto RG, Castellanos FX. A meta-analysis of neuropsychological functioning in patients with early onset schizophrenia and pediatric bipolar disorder. Journal of Clinical Child and Adolescent Psychology. 2011; 40:266-280.

19. Mysula Y, Venger O. Osoblyvosti astenichnoi ta obsesyvnoi symptomatyky u khvorykh z pervynnym epizodom bipoliarnoho afektyvnoho rozladu.
ScienceRise: Medical Science 2020; 1(34):41-45

20. Peters AT, Peckham AD, Stange JP, Sylvia LG, Hansen NS, Salcedo S, Deckersbach T. Correlates of real-world executive dysfunction in bipolar I disorder. Journal of Psychiatric Research. 2014;53:87-93.

21. Bourne C, Aydemir Ö, Balanzá-Martínez V, Bora E, Brissos S, Cavanagh JT, Clark L, Cubukcuoglu $Z$ et al. Neuropsychological testing of cognitive impairment in euthymic bipolar disorder: An individual patient data meta-analysis. Acta Psychiatrica

Scandinavica. 2013 Sep;128(3):149-162. 